\title{
Variation in Leaf Surface Hydrophobicity of Wetland Plants: the Role of Plant Traits in Water Retention
}

\author{
Daria Sikorska $^{1}$ (D) Ewa Papierowska ${ }^{1} \cdot$ Jan Szatylowicz $^{1} \cdot$ Piotr Sikorski $^{2}$. \\ Katarzyna Suprun $^{1} \cdot$ Richard J. Hopkins ${ }^{3}$
}

Received: 15 December 2016/Accepted: 31 May 2017 /Published online: 12 June 2017

(C) The Author(s) 2017. This article is an open access publication

\begin{abstract}
Leaf surface wetness has numerous physiological and ecological consequences, and the morphological structures on the leaf surface can affect its extent and duration, contributing to interception rates in the scale of the whole ecosystem. Wetland plants have developed morphological adaptations to high water level allowing them to avoid water excess. Droplet contact angle and surface free energy are measurable parameters which relate to how the plant influences water usage and redistribution. We analysed patterns of contact angle and the surface free energy of the adaxial and abaxial surface of 10 wetland plant species and related them to the optimal habitat conditions and functional traits of the plants. Despite the consistent environment of these plants, we found them to vary greatly in terms of leaf surface wettability and surface free energy, with contact angles ranging from 75 to $169^{\circ}$ and surface free energy, from 1.32 to $30.38 \mathrm{~mJ} / \mathrm{m}^{2}$. Canopy height and leaf longevity were significantly correlated to leaf wettability, whilst SLA (Specific Leaf Area) and leaf shape were not related to hydrophobicity. Investigating adaptations of wetland plants to their environment showed that including wettability and surface free energy in combination with other plant traits improves our
\end{abstract}

Daria Sikorska

daria_sikorska@sggw.pl

1 Faculty of Civil and Environmental Engineering, Warsaw University of Life Sciences - SGGW, ul. Nowoursynowska 159, 02-776 Warsaw, Poland

2 Faculty of Horticulture, Biotechnology and Landscape Architecture, Warsaw University of Life Sciences - SGGW, ul. Nowoursynowska 159, 02-776 Warsaw, Poland

3 Natural Resources Institute, University of Greenwich, Central Avenue, Chatham Maritime, Kent ME4 4TB, UK understanding of water plant-soil-water interactions in wetland habitats.

Keywords Leaf wettability · Water repellency · Plant funcional traits - Contact angle - Surface free energy . Interception

\section{Introduction}

Water retention is widely recognized as an important ecosystem service provided by wetlands (Mitsch and Gosselink 2000; Grygoruk et al. 2013; McInnes 2013). The vegetation of wetland ecosystems depends on the quantity and quality of water available (Kopeć et al. 2013), yet by intercepting water on their surface, plants alter hydrological conditions within the ecosystem. Vegetation architecture influences rainfall interception, and forest trees can retain up to $40 \%$ of rain (Rutter et al. 1972; Mitsch and Gosselink 2000). The interception rates of herbaceous plants are less investigated than those of forest trees, although values comparable to woodlands have been reported in open habitats (Gilman 1994). Reeds can store $4 \mathrm{~mm}$ of precipitation, moss-dominated peatlands $3 \mathrm{~mm}$ and sedges (Carex sp.) $2 \mathrm{~mm}$ (Ignar et al. 2013), making a significant contribution to the water storage function of wetland. Water pooled on the leaf surface can be used by the plant (foliar uptake), redistributed as stemflow or lost to evapotranspiration (Gómez et al. 2001; Eller et al. 2013).

Whether water remains on the surface of the leaf or is repelled depends on numerous leaf properties, including wax layer thickness and composition (Holloway 1969; Tanakamaru et al. 1998), trichomes or the number and distribution of stomata (Brewer and Nuñez 2007). Leaf wetting further affects numerous ecological processes, such as photosynthesis rate (Hanba et al. 2004), pathogen 
infection (Rowlandson et al. 2015) or absorption and removal of pollutants (Neinhuis and Barthlott 1997). Plant ability to repel water from the leaf surface can be termed as its hydrophobicity and can be comprehensively described by measuring the contact angle (CA) between a water droplet and the leaf surface (Bradley et al. 2003). Low angle values indicate high surface wettability, while high angle values indicate that water droplets form a spherical shape which more easily glides from the plant, making the plant non-wettable (Rosado and Holder 2013). Plant surfaces range from super hydrophilic $\left(\mathrm{CA}<40^{\circ}\right)$ to extremely hydrophobic $\left(\mathrm{CA}>150^{\circ}\right)$ (Brewer and Smith 1997; Brewer and Nuñez 2007). Another property of the leaf surface which affects water redistribution is the adhesion of water to the leaf surface which can also contribute to self-purification processes, an important factor in inundated areas. A parameter found to be positively correlated with adhesion forces is the surface free energy (SFE) (Wang et al. 2014). Plant leaves characterized by high SFE hold water droplets to their surface. A hydrophobic layer of waxes is reported to decrease the SFE so that as the droplet rolls off the leaf it collects dirt particles from the surface (Wang et al. 2015). Both leaf wettability and SFE contribute to water redistribution in plant-soil ecosystems and can be perceived as plant responses to environmental conditions. Understanding vegetation water use and its scale dependence has the potential to explain a significant proportion of the water balance and its variability in valuable water-dependent ecosystems.

In this study, we measure the CA and SFE of 10 plant species common in peat bogs to determine the relationship between parameters explaining the water distribution by plants (CA and the SFE) on adaxial and abaxial leaf surfaces with environmental parameters and plant functional traits. We predict that plants in the investigated peat-bog ecosystem possess differentiated strategies towards water interception which can be revealed in a wide range of wettability and SFE of the leaf surface. We also suggest that measured CA and SFE can be linked to plant functional traits and habitat parameters, thus revealing diverse strategies within a broad and varied ecological niche. By assessing CA and SFE, we can better understand plant adaptation but also model interception rates in the wetland ecosystem undergoing negative changes when changes in plant communities occur. This can be important in the light of the drying of these ecosystems and the wettability of the leaves may impede or accelerate drainage by directing water into the soil or storing it on the plant surface. The results of the study allow us to better understand the role of plant traits in the water interception of whole ecosystems and will also allow us to better understand the role of wetland ecosystems in water storage on a global scale.

\section{Materials and Methods}

During the 2013 vegetation season leaf material was collected from a degraded peat-bog located in Central Poland, coordinates $52^{\circ} 11^{\prime} 18^{\prime \prime} \mathrm{N} ; 21^{\circ} 14^{\prime} 6^{\prime \prime} \mathrm{E}$. The annual mean temperature for this region was about $9.4^{\circ} \mathrm{C}$ and annual precipitation was $584 \mathrm{~mm}$ (data for Warsaw during 2013-2015, Institute of Meteorology and Water Management). The site has been drained, used as a meadow and irregularly mown, degradation of the upper peat layer can be observed. 10 plant species were selected for the wettability assessment, characterized by high frequency within the site and representing common plant communities occurring on peat-bogs, but also those regarded as appearing due to habitat degradation (e.g. reed). The plants, despite occurring across the whole site are characterized by various optimum ecological conditions, in terms of moisture (values from 5 to 9 according to Ellenberg indicator values, Ellenberg et al. 1992) and nitrogen (Ellenberg values 2-5). Leaves were randomly collected from younger and older individuals. Investigated species were: Betula pendula Roth (Betulaceae), Carex acutiformis Ehrh. (Cyperaceae), Comarum palustre L. (Rosaceae), Filipendula ulmaria (L.) Maxim. (Rosaceae), Lathyrus palustris L. (Fabaceae), Ledum palustre L. (Ericaceae), Lysimachia vulgaris L. (Primulaceae), Lythrum salicaria L. (Lythraceae), Phragmites australis (Cav.) Trin. ex Steud. (Poaceae), Salix cinerea L. (Salicaceae).

The collected leaves were transported to the laboratory and air dried for a week. We used dry material because initial wetness has an effect on the measured contact angles and to achieve the same initial conditions for all species. Also leaves of most investigated plants (e.g. sedges and reeds) remain on the surface of the ground during the dormancy season and we wanted to find out if the presence of these plants could affect water interception. The leaves were gently placed (not pressed) between soft cloth in a horizontal attitude, to avoid damage to surface structures. Prior to the measurement, the leaf was gently flattened and attached to a microscope slide. For contact angle (CA) measurement we used 9 leaves for the adaxial and abaxial side where we placed one water droplet per leaf. To determine SFE, we used 9 leaves per liquid (water, formamide, ethylene glycol) separately for the adaxial and abaxial surface. The wetting CA were determined in the laboratory at $20^{\circ} \mathrm{C}$. Leaf wettability was obtained by the sessile drop method using goniometer CAM 100 (KSV Instruments, Finland). A $10 \mu \mathrm{L}$ droplet (Schreiber 1996) of distilled water was placed onto the leaf surface using a syringe. The CA were evaluated by calculating the slope of the tangent between the droplet at the liquid-solid-vapor interface line at both left and the right side using compatible software. The wettability of the plants leaf surfaces was classified as highly wettable, wettable, non-wettable or highly non-wettable (Aryal and Neuner 2010). The surface free energy (SFE) was determined 
according to Owens and Wendt (1969), as consisting of two components: dispersive and polar. The method is based on the CA measurements of three different liquids deposited on to a leaf surface: water, formamide and ethylene glycol, characterized by known SFE values, and calculated according to Goebel et al. (2004).

CA and SFE were linked to habitat properties, expressed as Ellenberg indicator values for moisture and nitrogen (Ellenberg et al. 1992). These indicators were selected as best representing changes that can occur due to habitat degradation and we suspect them to be linked most to hydrophobicity of plants. Plant functional traits, associated with biomass production such as: leaf size (in $\mathrm{cm}^{2}$ ), leaf persistence (leaf longevity, years), SLA specific leaf area (fresh leaf area to leaf biomass ratio $-\mathrm{mm}^{2}$ / $\mathrm{mg}$ ), obtained from databases: BiolFlor (http://www.ufz.de/ biolflor/overview/gattung.jsp) and LEDA (http://www.unioldenburg.de/en/biology/landeco/research/projects/leda/).

Spearman correlation coefficients were calculated between CA, SFE interaction with plants functional traits and habitat parameters at $p<0.05$ using Statistica 10 software (StatSoft Inc 2011).

\section{Results}

The investigated plants varied greatly in terms of the measured contact angles (Fig. 1), which ranged from 81 to $138^{\circ}$ for the adaxial surface of the leaf and from $94^{\circ}$ to $160^{\circ}$ for the abaxial surface. Most species revealed higher hydrophobicity on the abaxial surface of the leaf, with the exception of Phragmites australis, which had a much higher hydrophobicity on the adaxial surface.

The calculated SFE of the plants tested ranged from 1.32 to $30.38 \mathrm{~mJ} / \mathrm{m}^{2}$ (Table 1 ). The leaves of most species were categorized as non-wettable or highly non-wettable, exceeding
CA $120^{\circ}$. Differences in the calculated SFE with dispersion and polar components are shown in Table 1 . The highest values of SFE were for $B$. pendula and $C$. acutiformis, the lowest for $L$. palustris and $P$. australis. In the case of L. palustre and $C$. acutiformis the SFE on both surfaces of the leaves consists exclusively of the dispersal component. In other plants, such as $F$. ulmaria and $C$. palustre for the adaxial surface the dominant is the dispersive component, while for the abaxial surface the polar component. In L. palustris and L. salicaria, this pattern is reversed.

Relationships between wettability, surface free energy and habitat conditions were observed in wetland species. Hydrophobicity of the adaxial surface of the leaves was found to be significantly correlated to the habitat moisture, expressed with Ellenberg indicator values $(r=0.85, \mathrm{df}=9, p=0.002)$. Water repellent surfaces were found in plants occurring in wetter conditions, but also the greater the moisture of the environment, the less the adaxial surfaces of the leaves retained water droplets (SFE $r=-0.69, \mathrm{df}=9, p=0.027$ ). The wettability and SFE of the abaxial side of the plant leaves, however, were not related to the habitat moisture level (Table 2). The relationship between SFE and plant traits was only found for the adaxial surface of the leaves significant correlations were found with longevity of stems $(r=-0.72$, df $=9, p=0.018)$ and canopy height $(r=-0.68$, df $=9, p=0.018)$.

Among the plant traits investigated, we found longevity of stems to be significantly correlated to leaf wettability of both the adaxial and the abaxial surface of the leaf (adaxial $r=-0.72$, df $=9, p=0.018^{*}$, abaxial $r=-0.65$, df $=9$, $p=0.040)$ Height was only correlated with hydrophobicity of the adaxial surface $(r=-0.68, \mathrm{df}=9, p=0.030)$ (Table 2). Nitrogen content, specific leaf area and leaf size were not related to hydrophobicity of neither the adaxial nor abaxial surface of the leaf (Table 2).
Fig. 1 Contact angle (CA) values for leaves of selected wetland plants species, median values shown with horizontal lines and the hydrophobicity assessment scale proposed by Aryal and Neuner (2010)

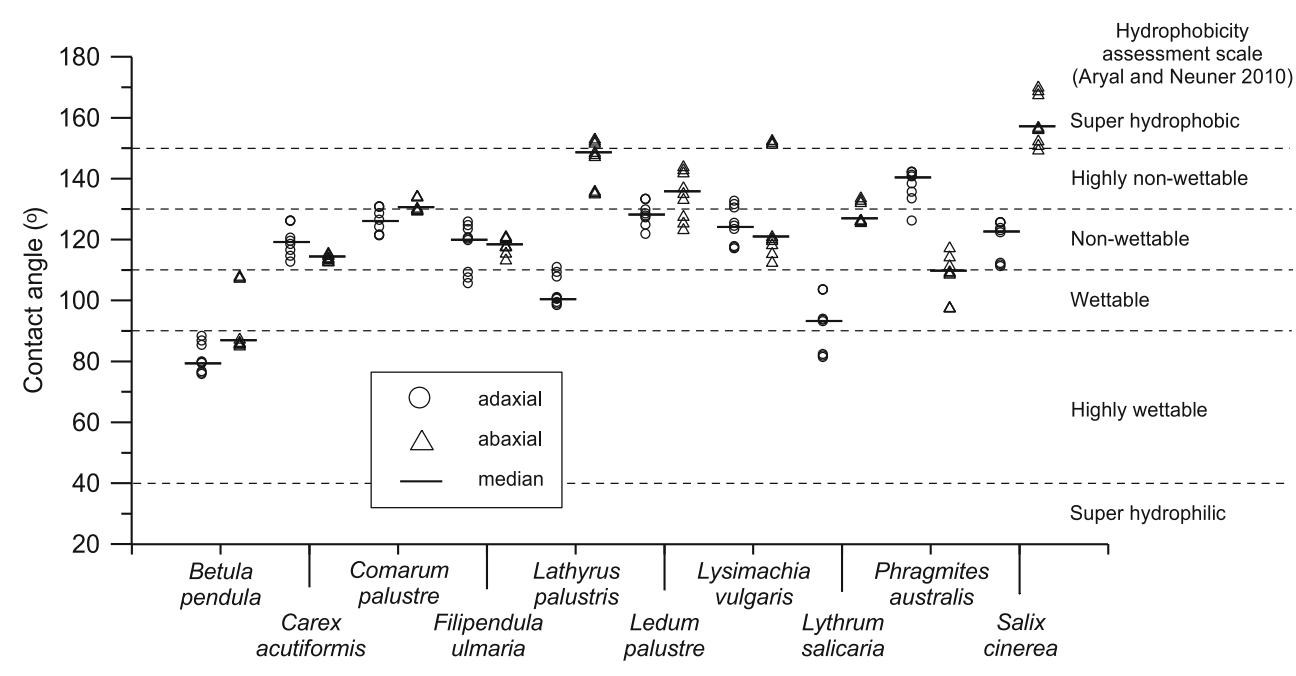


Table 1 Surface free energy (SFE) and its components calculated for adaxial and abaxial side of the leaves of selected plant species

\begin{tabular}{|c|c|c|c|c|}
\hline \multirow[t]{2}{*}{ Species } & \multirow[t]{2}{*}{ Leaf side } & \multicolumn{2}{|c|}{ Components of SFE $\left(\mathrm{mJ} / \mathrm{m}^{2}\right)$} & \multirow[t]{2}{*}{$\operatorname{SFE}\left(\mathrm{mJ} / \mathrm{m}^{2}\right)$} \\
\hline & & Dispersion & Polar & \\
\hline \multirow[t]{2}{*}{ Betula pendula } & adaxial & 0.54 & 29.57 & 30.12 \\
\hline & abaxial & 4.09 & 11.79 & 15.88 \\
\hline \multirow[t]{2}{*}{ Carex acutiformis } & adaxial & 16.61 & 0.00 & 16.61 \\
\hline & abaxial & 30.38 & 0.00 & 30.38 \\
\hline \multirow[t]{2}{*}{ Comarum palustre } & adaxial & 13.12 & 0.00 & 13.12 \\
\hline & abaxial & 0.46 & 1.54 & 2.00 \\
\hline \multirow[t]{2}{*}{ Filipendula ulmaria } & adaxial & 6.10 & 1.30 & 7.40 \\
\hline & abaxial & 0.01 & 5.13 & 5.13 \\
\hline \multirow[t]{2}{*}{ Lathyrus palustris } & adaxial & 0.01 & 13.13 & 13.13 \\
\hline & abaxial & 1.29 & 0.03 & 1.32 \\
\hline \multirow[t]{2}{*}{ Ledum palustre } & adaxial & 19.59 & 0.00 & 19.59 \\
\hline & abaxial & 10.18 & 0.00 & 10.18 \\
\hline \multirow[t]{2}{*}{ Lysimachia vulgaris } & adaxial & 2.04 & 1.67 & 3.71 \\
\hline & abaxial & 1.71 & 0.98 & 2.69 \\
\hline \multirow[t]{2}{*}{ Lythrum salicaria } & adaxial & 6.47 & 10.23 & 16.70 \\
\hline & abaxial & 8.09 & 0.00 & 8.09 \\
\hline \multirow[t]{2}{*}{ Phragmites australis } & adaxial & 0.13 & 1.28 & 1.41 \\
\hline & abaxial & 0.01 & 12.73 & 12.73 \\
\hline \multirow[t]{2}{*}{ Salix cinerea } & adaxial & 1.99 & 2.52 & 4.51 \\
\hline & abaxial & 2.04 & 0.00 & 2.04 \\
\hline
\end{tabular}

\section{Discussion}

Leaf surface characteristics contribute to variability in the amount of water pooled on the surface of plants, and thus alter rainfall interception in the scale of the whole catchment. This study shows several distinct strategies taking place in wetland

Table 2 Spearman correlation coefficient and $p$ values between CA, SFE and properties of leaves

\begin{tabular}{lllll}
\hline Properties of leaves & $\begin{array}{l}\mathrm{CA}- \\
\text { adaxial }\end{array}$ & $\begin{array}{l}\mathrm{CA}- \\
\text { abaxial }\end{array}$ & $\begin{array}{l}\mathrm{SFE}- \\
\text { adaxial }\end{array}$ & $\begin{array}{l}\text { SFE - } \\
\text { abaxial }\end{array}$ \\
\hline Ellenberg: Moisture (-) & 0.85 & 0.34 & -0.69 & -0.04 \\
& $0.002^{*}$ & 0.343 & $0.027^{*}$ & 0.918 \\
Ellenberg indicator & 0.31 & -0.22 & -0.45 & 0.40 \\
$\quad$ - Nitrogen (-) & 0.381 & 0.538 & 0.193 & 0.246 \\
Longevity of & -0.72 & -0.65 & 0.72 & 0.28 \\
stems (years) & $0.018^{*}$ & $0.040^{*}$ & $0.019^{*}$ & 0.425 \\
Canopy height (m) & -0.68 & -0.62 & 0.65 & 0.26 \\
& $0.030^{*}$ & 0.055 & $0.041^{*}$ & 0.466 \\
Leaf size (cm $\left.{ }^{2}\right)$ & 0.41 & -0.24 & -0.53 & -0.10 \\
& 0.233 & 0.505 & 0.116 & 0.778 \\
SLA $\left(\mathrm{mm}^{2} / \mathrm{mg}\right)$ & -0.49 & -0.46 & 0.29 & -0.03 \\
& 0.155 & 0.183 & 0.416 & 0.930 \\
\hline
\end{tabular}

$p$ values are presented in italics

$S F E$ surface free energy $\left(\mathrm{mJ} / \mathrm{m}^{2}\right), C A$ contact angle $\left(^{\circ}\right), S L A$ specific leaf area

*marked correlations are significant at $p<0.05$ plants in terms of ability to repel water from their surface. Measured contact angle and free surface energy, used as measures of leaf hydrophobicity, varied greatly in wetland plant species. This study found a link between leaf wettability and habitat moisture, showing the leaf wettability to be stronger in plants with a high canopy and in plants with extended leaf longevity. The study found wettability and free surface energy to be possible measures of plants adaptation to their environment.

Leaf wettability, when treated as an intra-specific adjustment to the environment, has been proved to change along environmental gradients, such as altitude (Aryal and Neuner 2010; Goldsmith et al. 2017) and moisture (Brewer and Nuñez 2007; Holder 2007a), but these studies show gradients along different habitats. Moreover plants from wetter habitats are not necessarily characterised by higher hydrophobicity (Holder 2007b). The surface of the wetland plants is in general hydrophobic and in most plants the leaves repel water rather than retain it. This only concerns the upper surface of the leaf. No such relationship is visible for the lower surface of the leaf. Wetland habitats are characterized by much higher plant transpiration rates and there is usually much more water available (Kelvin et al. 2017), thus they do not need additional water sources.

The results of this study demonstrate that most wetland species are characterized by a high abaxial surface hydrophobicity compared to most crop species (Shujie 
et al. 2016), emphasizing the importance of determining the strategies of specific plant groups to water discharge. The study focused on moisture variance within a broadly homogenous environment, and found that plants vary widely in their water discharge possibly due to either niche adaptions or to different strategies. Most of the plants investigated were characterized by high CA and SFE and among species investigated three functional groups could be distinguished - species typical for: rushes, wet meadows, and bogs/fens. The first group: P. australis, L. vulgaris and S. cinerea, occur in close proximity to water and is subjected to inundation, share low SFE (1.41 to $4.51 \mathrm{~mJ} / \mathrm{m}^{2}$ ) and highly nonwettable leaf surface (CA from 137.71 to $159.51^{\circ}$ ). These species shed the surplus water from their surface, additionally improving self-cleaning. In more elevated areas, such as wet meadows, inundation occurs seldom and is mostly limited to lower plant parts. For species occurring there, such as: L. salicaria, F. ulmaria, and L. palustris, SFE ranges from 7.4 to $16.70 \mathrm{~mJ} / \mathrm{m}^{2}$, and hydrophobicity is low varying from $92.70^{\circ}$ to $117.17^{\circ}$. These plants retain water on their leaf surface more than species which are often inundated. Species more typical for bogs and fens: L. palustre, and C. palustre, are seldom subjected to water logging, and have a very high SFE (13.12 to $\left.19.95 \mathrm{~mJ} / \mathrm{m}^{2}\right)$ and their leaves are moderately hydrophobic (CA from 125.92 to $128.59^{\circ}$ ). Plants growing in frequently flooded sites avoid the risk of leaf and stem deformation due to wetting while in drier habitats plants retain water on their leaves surface. Species such as $S$. cinerea, L. palustris, and L. salicaria form structures on the abaxial surface of the leaves allowing an increase of hydrophobicity by $30-40 \%$, mostly due to high pubescence. The adaxial surface is more subjected to environmental factors and water loss, whilst the abaxial surface bears most of the stomata. Most species revealed higher hydrophobicity of the adaxial surface, which is typical for wetland plants (Neinhuis and Barthlott 1997). The abaxial and adaxial surface of the leaves differ in terms of quantity and composition of waxes between plant species (Gniwotta et al. 2005). Water retained on the plant surface influences the ecosystem at the scale of the plants physiology (reviewed Wang et al. 2015), but also affect the function of the ecosystem (Holder 2007b).

Across the range tested here, the ability of plants to repel water from the surface was correlated with stem life-span, longer living plants and plants with a tall canopy retain water to a greater extent. This phenomenon might be important in wetlands where taller woody plants overgrow the bogs and by their high transpiration rate contribute to lowering of the groundwater table (Woziwoda and Kopeć 2014). Additionally, capturing water on their surface, and decreasing throughfall they can have an effect on the overall water cycle. There can also be differences depending on the species overgrowing the bogs - S. cinerea characterized by high hydrophobicity will have a lesser effect on interception than $B$. pendula which has highly wettable leaves and captures more water.

No correlations were found with SLA, although, lower values of SLA tend to correspond with a long leaf lifespan and species with a high investment in leaf structural defenses. Some shade-tolerant woodland understory species and species in resource-rich environments have remarkably high SLA (Cornelissen et al. 2003), but this was not confirmed in this study. The relationships between CA and SFE and plant traits were found for both adaxial and abaxial surfaces of the leaves but SFE on the abaxial surface was not related to any of the traits measured. Ignar et al. (2013) demonstrated that interception in wetlands had been underestimated and can account for a substantial share of the rainfall. Knowing plant's individual strategies allows us to forecast how much water will be retained on the plant surface. Knowing the composition of plants and their features will thus allow us to improve the accuracy of hydrological models. The drying of wetlands which are overgrown with plants characterized by wettable leaves will result in a reduction of the water directed into the soil, instead water will be retained on the surface of the plants from where it may evaporate. Thus, in drier parts of the wetlands, the amount of water stored on the surface is higher after land drainage. Drained wetlands are often characterized by higher soil water retention in comparison to undrained areas with the same physical characteristics (Mioduszewski and Wassen 2000), and the role of vegetation storage is increased in such degraded habitats. Descriptions of the precipitation process seldom include vegetation interception, which stores water on the surface of the plants and enhances evaporation. Also, the CA and SFE values reported are slightly lower in dry plants because the leaf surface is unable to stretch while fresh leaves are pliable and deform, creating a larger contact area for a water droplet (Wagner et al. 2003; Bhushan and Jung 2011). However during winter months the vegetation in these ecosystems may still retain the properties to store water on plant surfaces, which should be taken into account when describing hydrological process in wetlands. This research indicates the importance of interception during vegetation dormancy periods, when wetland plants store water on their surface and strongly influence the rainfall-runoff process. Here, investigating adaptations of wetland plants to their environment showed that wettability and SFE in combination with other plant traits improves our understanding of the water discharge processes. Both wettability and SFE have the potential to be used as bioindicators for the degradation of wetland habitats and require further investigation. 
Acknowledgements The study was funded by the National Science Centre (NCN), Poland, No. 2012/05/B/NZ9/03467.

Open Access This article is distributed under the terms of the Creative Commons Attribution 4.0 International License (http:// creativecommons.org/licenses/by/4.0/), which permits unrestricted use, distribution, and reproduction in any medium, provided you give appropriate credit to the original author(s) and the source, provide a link to the Creative Commons license, and indicate if changes were made.

\section{References}

Aryal B, Neuner G (2010) Leaf wettability decreases along an extreme altitudinal gradient. Oecologia 162(1):1-9

Bhushan B, Jung YC (2011) Natural and biomimetic artificial surfaces for superhydrophobicity, self-cleaning, low adhesion, and drag reduction. Progress in Materials Science 56:1-108

Bradley DJ, Gilbert GS, Parker IM (2003) Susceptibility of clover species to fungal infection: the interaction of leaf surface traits and environment. American Journal of Botany 90(6):857-864

Brewer CA, Nuñez CI (2007) Patterns of leaf wettability along an extreme moisture gradient in western Patagonia, Argentina. International Journal of Plant Sciences 168(5):555-562

Brewer CA, Smith WK (1997) Patterns of leaf surface wetness for montane and subalpine plants. Plant, Cell and Environment 20(1):1-11

Cornelissen JHC, Lavorel S, Garnier E, Diaz S, Buchmann N, Gurvich DE, Reich PB, ter Steege H, Morgan HD, van der Heijden MGA, Pausas JG, Poorter H (2003) A handbook of protocols for standardised and easy measurement of plant functional traits worldwide. Australian Journal of Botany 51(4):335-380

Ellenberg H, Weber HE, Düll R, Wirth V, Werner W, Paulißen D (1992) Zeigerwerte von Pflanzen in Mittel-europa, 2nd ed. Scripta Geobotanica 18:1-258

Eller CB, Lima AL, Oliveira RS (2013) Foliar uptake of fog water and transport belowground alleviates drought effects in the cloud forest tree species, Drimys Brasiliensis (Winteraceae). The New Phytologist 199:151-162

Gilman K (1994) Hydrology and wetland conservation. Wiley, Chichester

Gniwotta F, Vogg G, Gartmann V, Carver TL, Riederer M, Jetter R (2005) What do microbes encounter at the plant surface? Chemical composition of pea leaf cuticular waxes. Plant Physiology 139(1):519-530

Goebel MO, Bachmann J, Woche SK, Fischer WR, Horton R (2004) Water potential and aggregate size effects on contact angle and surface energy. Soil Science Society of America Journal 68(2):383-393

Goldsmith GR, Bentley LP, Shenkin A, Salinas N, Blonder B, Martin RE, Castro-Ccossco R, Chambi-Porroa P, Diaz S, Enquist BJ, Asner GP, Malhi Y (2017) Variation in leaf wettability traits along a tropical montane elevation gradient. The New Phytologist 214(3):989-1001

Gómez JA, Giráldez JV, Fereres E (2001) Rainfall interception by olive trees in relation to leaf area. Agricultural Water Management 49(1): 65-76

Grygoruk M, Mirosław-Świątek D, Chrzanowska W, Ignar S (2013) How much for water? Economic assessment and mapping of floodplain water storage as a catchment-scale ecosystem service of wetlands. Water 5(4):1760-1779

Hanba YT, Moriya A, Kimura K (2004) Effect of leaf surface wetness and wettability on photosynthesis in bean and pea. Plant, Cell and Environment 27(4):413-421

Holder CD (2007a) Leaf water repellency as an adaptation to tropical montane cloud forest environments. Biotropica 39(6):767-770
Holder CD (2007b) Leaf water repellency of species in Guatemala and Colorado (USA) and its significance to forest hydrology studies. Journal of Hydrology 336(1-2):147-154

Holloway PJ (1969) The effects of superficial wax on leaf wettability. The Annals of Applied Biology 63(1):145-153

Ignar S, Weglewska A, Szporak-Wasilewska S, Chormański J (2013) Spatial and temporal variability of the interception in the natural wetland valley, the lower Biebrza basin case study. Annals of Warsaw University of Life Sciences-SGGW. Land Reclamation 45(1):111-119

Kelvin J, Acreman MC, Harding RJ, Hess TM (2017) Micro-climate influence on reference evapotranspiration estimates in wetlands. Hydrological Sciences Journal 62(3):378-388

Kopeć D, Michalska-Hejduk D, Krogulec E (2013) The relationship between vegetation and groundwater levels as an indicator of spontaneous wetland restoration. Ecological Engineering 57:242-251

McInnes RJ (2013) Recognizing ecosystem services from wetlands of international importance: an example from Sussex, UK. Wetlands 33(6):1001-1017

Mioduszewski W, Wassen MJ (eds) (2000) Some aspects of water management in the valley of Biebrza river. Institute for Land Reclamation and Grassland Farming, Falenty

Mitsch W, Gosselink J (2000) Wetlands, 3rd edn. Wiley, New York

Neinhuis C, Barthlott W (1997) Characterization and distribution of water-repellent, self-cleaning plant surfaces. Annals of Botany 79(6): 667-677

Owens DK, Wendt RC (1969) Estimation of the surface free energy of polymers. Journal of Applied Polymer Science 13(8):1741-1747

Rosado BH, Holder CD (2013) The significance of leaf water repellency in ecohydrological research: a review. Ecohydrology 6(1):150-161

Rowlandson T, Gleason M, Sentelhas P, Gillespie T, Thomas C, Hornbuckle B (2015) Reconsidering leaf wetness duration determination for plant disease management. Plant Disease 99(3):310-319

Rutter AJ, Kershaw KA, Robins PC, Morton AJ (1972) A predictive model of rainfall interception in forests, 1 . Derivation of the model from observations in a plantation of Corsican pine. Agricultural Meteorology 9:367-384

Schreiber L (1996) Wetting of the upper needle surface of Abies grandis: influence of $\mathrm{pH}$, wax chemistry and epiphyllic microflora on contact angles. Plant, Cell \& Environment 19(4):455-463

Shujie W, Hujun W, Chun L, Xiangmei Z, Hui H, Yajun Z (2016) Adsorption characteristics of droplets applied on non-smooth leaf surface of typical crops. International Journal of Agricultural and Biological Engineering 9(1):35-41

StatSoft, Inc (2011) STATISTICA (data analysis software system) version 10. www.statsoft.com

Tanakamaru S, Takehana T, Kimura K (1998) Effect of rainfall exposure on leaf wettability in near-isogenic barley lines with different leaf wax content. Journal of Agricultural Meteorology 54(2):155-160

Wagner P, Fürstner R, Barthlott W, Neinhuis C (2003) Quantitative assessment to the structural basis of water repellency in natural and technical surfaces. Journal of Experimental Botany 54:1295-1303

Wang H, Shi H, Li Y, Wang Y (2014) The effects of leaf roughness, surface free energy and work of adhesion on leaf water drop adhesion. PloS One 9(9):e107062

Wang H, Shi H, Wang Y (2015) The wetting of leaf surfaces and its ecological significances. In: Aliofkhazrei M (ed) Wetting and wettability. InTech. doi:10.5772/61205

Woziwoda B, Kopeć D (2014) Afforestation or natural succession? Looking for the best way to manage abandoned cut-over peatlands for biodiversity conservation. Ecological Engineering 63:143-152 